Atıf için: Karadaş K, Güler F, 2021. Iğdır İlinde Domates Üretim Maliyetinin Belirlenmesi. Iğdır Üniversitesi Fen Bilimleri Enstitüsü Dergisi, 11(3): 2350-2356.

To cite: Karadaş K, Güler F, 2021. Determination of Tomato Production Cost in Iğdır Province. Journal of the Institute of Science and Technology, 11(3): 2350-2356.

\title{
Iğdır İlinde Domates Üretim Maliyetinin Belirlenmesi
}

$$
\text { Köksal KARADAŞ }{ }^{*} \text {, Fatih GÜLER }{ }^{2}
$$

ÖZET: Bu çalışmanın amacı Iğdır İlinde domates üretim maliyetini belirlemektir. Çalışmada Iğdır ve İlçelerinde Basit Tesadüfi Örnekleme Yöntemi ile belirlenen 105 adet domates üreten işletmeden elde edilen veriler kullanılmıştır. Domates maliyetinin hesaplanmasında "Tek Ürün Bütçe Analiz Yöntemi” kullanılmıştır. Çalışmada işletmelerin ortalama $6.07 \mathrm{da}$ alanda domates ürettikleri ve dekara $5454.76 \mathrm{~kg}$ ürün elde ettikleri belirlenmiştir. Ürün satış fiyatı $0.29 \$ \mathrm{~kg}^{-1}$, birim maliyet $0.15 \$ \mathrm{da}^{-1}$ olup bölge domates üreticisi kg başına $0.14 \$$ net kâr elde etmiştir. Dekara üretim masrafi toplamı 830.90 \$, Gayri Safi Üretim Değeri (GSÜD) 1608.36 \$, Brüt Kâr 844.70 \$ ve Net Kâr ise 777.71 \$ olarak hesaplanmıştır. Üretim masraflarının \%91.94'ünü değişen masraflar, \%8.06'sını ise sabit masraflar oluşturmaktadır. Değişen masraflar içerisinde en fazla payı \%45.18 ile hasat masrafları alırken; sabit masraflar içerisinde en fazla pay1 \%65.78 ile tarla kirası almaktadır. Dekara 3.64 \$ mazot ve gübre desteği alan domates üreticisi çalışmanın yapıldığı 2016 yılında domatesin değer fiyattan satılması sonucu üretim faaliyetini kârlı bir şekilde tamamlamıştır. Ürün işleme tesisi veya kooperatif kurmak gibi ürün pazar değerinin yeterli düzeyde gerçekleşmesini sağlayacak tedbirlerin alınması üreticinin üretim faaliyetine devam etmesi bakımından önem arz etmektedir.

Anahtar Kelimeler: Domates, Maliyet Analizi, Iğdır.

\section{Determination of Tomato Production Cost in Iğdır Province}

ABSTRACT: This study aims to determine tomato production costs in Iğdır province. In the study, the data obtained by simple random sampling method from 105 tomato producing establishments in Iğdır and its districts were used. "Single Product Budget Analysis Method" was used in the calculation of tomato cost. At the end of the study, it was determined that the farms produced tomatoes on an average of $6.07 \mathrm{da}$ and $5454.76 \mathrm{~kg}$ of product per hectare. The product price was $0.29 \$ \mathrm{~kg}^{-1}$, the unit cost was $0.15 \$ \mathrm{da}^{-1}$ and the regional tomato producer made a net profit of 0.14 \$ per kg. Total production cost per decare was 830.90 \$, Gross Production Value (GSÜD) was calculated as 1608.36 \$, Gross Profit was calculated as 844.70 \$ and Net Profit was calculated as 777.71 \$. Variable costs constituted $91.94 \%$ of the production costs while $8.06 \%$ were fixed costs. The harvest costs had the highest share in the variable costs (\%45.18) while the highest share in the fixed costs were those of the field rent (\%65.78). The tomato producer, who received fuel and fertilizer support of $3.64 \$$ per decare, completed the production activities profitably as a result of the sale of tomatoes at a value price in 2016. Taking measures to ensure that the product market value is realized at a sufficient level, such as product processing plant or establishing a cooperative, is important in terms of continuing the production activity of the producer.

Keywords: Tomato, Cost Analysis, Iğdır.

\footnotetext{
${ }^{1}$ Köksal KARADAŞ (Orcid ID: 0000-0003-1176-3313), Iğdır Üniversitesi, Ziraat Fakültesi, Tarım Ekonomisi Bölümü, Iğdır, Türkiye
} ${ }^{2}$ Fatih GÜLER (Orcid ID: 0000-0003-4550-634X), Yüzüncü Yıl Üniversitesi, İdari ve Mali İşler Daire Başkanlığı, Van, Türkiye

*Sorumlu Yazar/Corresponding Author: Köksal KARADAŞ, e-mail: kkaradas2002@gmail.com.tr 


\section{GíRiș}

Yaş sebze ve meyve grubundan olan ve dünyanın birçok ülkesinde yetiştirilebilen domates, başta insan sağlığı olmak üzere birçok yönden büyük öneme sahiptir. Taze veya işlenmiş olarak tüketilebilen domatesten konserve, salça, meyve suyu vb. ürünler yapılabilmekte olup, ürün sos, ketçap, turşu püre şeklin de tüketilebilmektedir (Keskin ve Gül, 2004). Domates sağlık bakımından büyük öneme sahip olup kanser, kardiyovasküler hastalıklar, prostat, bazı kronik hastalıklar, karaciğer hasarının önlenmesi gibi birçok hastalığın tedavisinde kullanılmaktadır (Muratore ve ark., 2008; Bhowmik ve ark., 2012). Domates içeriğinde $\mathrm{A}$ ve $\mathrm{C}$ vitamini bulunması yanında $\beta$ karoten, likopen, potasyum, minareller, flavonoidler, fitosteroller ve polifenoller gibi ikincil metabolitler kaynağı olarak bilinmektedir (Gutierrez, 2018). 2016 yılında dünyada 4850243 ha alanda 176857813 ton domates üretilip dekara 3 $646 \mathrm{~kg}$ verim alınırken (FAO, 2018), aynı yıl Türkiye'de 189371 ha alanda, 12600000 ton domates üretilmiş ve dekara 6654 kg verim alınmıştır (TÜİK, 2019). Çalışmanın yapıldığı 2016 yılında Iğdır'da 16804 dekar alanda 58763 ton ürün elde edilmiş ve dekara $3470 \mathrm{~kg}$ verim alınmıştır. Türkiye domates verimi dünya ortalamasının iki katı civarında olmasına karşın; Iğdır ilinde domates verimi Türkiye'deki verimin yarısı kadardır. Bu durum bölge üreticisinin eldeki kaynakları etkin ve verimli kullanamadığı sorusunu akla getirmekle birlikte yeterince kazanç sağlayamamaları sonucunu doğurmaktadır. Daha verimli kaynak kullanımı ise ürün maliyetlerinin azalmasına ve birim alandan daha yüksek ürün ve daha fazla brüt kâr elde edilmesine sebep olmaktadır (Karadaş, 2016). Brüt kâr işletmede bulunan kıt üretim faktörlerinin kullanımı açısından, üretim faaliyetlerinin karşılaştırılmasında kullanılan önemli bir başarı ölçüsü olup işletme organizasyonunun başarısını göstermektedir (Rehber ve Tipi, 2015). İşletmelerde ürün maliyetleri bir taraftan ürün fiyatlarının tespiti diğer taraftan üretimle ilgili alınacak kararların belirlenmesi, üretim planlaması, işletme faaliyetlerinin devamlılığının sağlanması, sürdürülebilir kâr vb. konular bakımından oldukça önemlidir. Kârlılık ise her zaman daha fazla ekim alanı veya daha fazla bitkisel veya hayvansal ürün elde edilmesi anlamını taşımamakla birlikte, optimum maliyet temeline dayanmaktadır. Tarımsal ürünlerin üretiminde kullanılan girdilerin miktar ve değer olarak belirlenmesi, maliyet ve en uygun girdi kullanımı ile sağlanabilecek optimum maliyete ulaşmak için gereklidir (Çetin ve Bahşi, 2019).

Her yıl enflasyonun görüldüğü ülkelerde tarımsal girdi fiyatlarındaki özellikle enflasyona bağglı artışlar, ürün maliyetlerini ve kâr düzeyini etkilemektedir. Bu yüzden tek yıllık veya çok yıllık tarımsal ürün maliyetlerinin her yıl yeniden hesaplanması tarım işletmeleri açısından önem arz etmektedir. Daha gerçekçi tarım politikalarının geliştirilebilmesi ve daha uygun üretim desenlerinin belirlenebilmesi için tarım ürünleri maliyetlerinin tespit edilmesi ve veri tabanında toplanması gereklidir.

Bölgede daha önce domates üretim maliyeti ile ilgili herhangi bir çalışma yapılmamış olması çalışmanın gerekliliğini ortaya koyarken, domates üretiminde kullanılan girdi düzeyleri, uygulama zamanları, ürün kârlılığının belirlenmesi ve domates üreticisinin başarısı açısından önem arz etmektedir. Bu çalışmanın amacı Iğdır İli tarım üreticisi için oldukça önemli bir ürün olan domatesin üretim maliyetini belirlemektir. Bu kapsamda domates üretiminde kullanılan girdiler ve değerleri, ürün maliyeti ve unsurları ile bu unsurların oranlarının belirlenerek işletmelerin domates üretimindeki kâr-zarar durumunun tespit edilmesi amaçlanmıştır.

\section{MATERYAL VE METOT}

\section{Materyal}

Araştırma alanı olan Iğdır ilinde domates üretimi yapan 105 çiftçi ile karşılıklı anket yapılarak elde edilen veriler araştırmanın ana materyalini oluştururken, domates üretimi ve ekonomisi hakkında 
yapılmış diğer araştırma ve incelemelerden, yerli ve yabancı yayınlardan, kamu kurum ve kuruluşları kayıtları ve istatistikî verilerinden faydalanılmıştır. Anket çalışması domates hasadından sonra TemmuzAğustos 2016 tarihleri arasında yapılmış olup çalışma 2016 üretim dönemini kapsamaktadır.

\section{Yöntem}

\section{Örnek işletmelerin belirlenmesinde uygulanan yöntem}

Çalışma alanı olarak, Iğdır ilinin domates yetiştiren işletme sayısının \%98'ini ve domates üretim alanının \%94'ünü oluşturan Merkez ve Karakoyunlu ilçeleri “Gayeli Örnekleme Yöntemi” ile seçilmiştir. Iğdır Merkez ve Karakoyunlu Tarım ve Orman İlçe Müdürlüklerinin domates üretimi yapan çiftçilerin domates üretim alan miktarlarını gösteren kayıtlar alındıktan sonra "Basit Tesadüfi Örnekleme” yapılarak (Yamane, 2010) \%90 güven düzeyi ve \%10 sapmayla örnek büyüklüğü 95 olarak hesaplanmış olup örnekleme formülü aşağıda verilmiştir. Ancak hatalı ve eksik veri bulunan anket ihtimaline karşı anket sayısı \%10 artırılarak örnek hacmi 105'e çıkarılmış olup çalışma 105 anket üzerinden yapılmış olup yedek 10 anket her iki ilçeye eşit dağıtılmıştır.

$\mathrm{n}$ : Populasyonu temsil edecek işletme sayısını,

$\mathrm{N}$ : Populasyondaki işletme sayısı toplamı (465),

$\mathrm{S}^{2}$ : Populasyonun varyansinı (33.17),

$\mathrm{D}$ : Düzeltme faktörünü ifade etmektedir.

Düzeltme faktörü $(\mathrm{D})=\left(\mathrm{E} \mathrm{t}^{-1}\right)^{2}$ formülünden elde edilmiş olup araştırmada t katsayısı $\% 90$ güven sınırları için 1.6445 olarak alınmıştır. E ise hata terimi olup (0.87), ilgili büyüklük grubu ortalamasının $\% 10$ 'udur.

$$
\begin{aligned}
& n=\frac{N S^{2}}{(N-1) D^{2}+S^{2}} \\
& n=\frac{465 \times 5.76^{2}}{(465-1)(0.87 / 1.6446)^{2}+5.76^{2}}=94.78
\end{aligned}
$$

Çizelge 1. İlçelere göre anket sayıları

\begin{tabular}{lccc} 
İlçe & İşletme sayısı & Örnek sayısı & \% \\
\hline Merkez & 239 & 55 & 51.9 \\
Karakoyunlu & 217 & 50 & 48.1 \\
Toplam & 456 & 105 & 100 \\
\hline
\end{tabular}

\section{Maliyet analizinde uygulanan yöntem}

Anket yoluyla ve çeşitli kurumların resmi kayıtlarından yararlanılarak elde edilen bilgiler Excel hesap tablosu programı yardımıyla düzenlenerek analize hazır hale getirilmiş ve SPSS paket programına aktarıldıktan sonra gerekli analizler yapılmıştır.

Tarımsal üretimde masraftan söz edildiğinde, belirli bir mahsulün üretimi için gerekli mal ve hizmetlerin parasal değerleri anlaşılmaktadır. Bir tarım işletmesinde masraflar, değişen ve sabit masraflar olarak tasnif edilmektedir. Sabit masraflar, üretim hacmine bağlı olarak değişmeyen masraflardır. Değişen masraflar ise, üretim hacmine bağlı olarak orantılı bir şekilde artan ya da eksilen masraflardır (Karagölge ve ark., 2013).

Değişen masraflar; gübre, ilaç, tamir-bakım, makine kirası, geçici işçilik, hasat ve pazarlama, sermaye faizinden oluşmaktadır. Toprak işleme masraflarının hesaplanmasında bölgedeki traktör ücretleri yani alternatif maliyet esas alınmıştır. Sabit masraflar; genel idare giderleri, çıplak arazi değeri faizi ve tesis masrafları ve amortisman payından oluşmaktadır. Üretim girdilerinin birim fiyatı belirlenirken, üreticinin söz konusu girdiyi kullandığı dönemdeki fiyatlar dikkate alınmıştır. 
Değişen masrafların faizi (döner sermaye faizi), firsat maliyetini temsil etmektedir. Basit olarak değişken giderler için yapılan harcama miktarı başka bir alanda değerlendirilmiş olsa idi, belirli bir faiz geliri sağlayacaktı. Bu harcama miktarının üretimde kullanılması ile faiz gelirinden vazgeçilmiş olunmaktadır. Bundan dolayı masraf olarak değerlendirilmesi gerekmektedir. Türkiye'de bu amaçla sermayenin tarımsal üretimde kaldığı süreler ile T.C. Ziraat Bankası'nın tarımsal kredi faizi dikkate alınmaktadır (Kıral ve Kasnakoğlu, 1999). T.C Ziraat Bankası'nın tarımsal amaçlı alınan kredilere uygulamış olduğu 2016 yılı için yıllık faiz oranının yarısı (\%4.8) hesaplamada kullanılmıştır. Genel idari giderler, değişken masrafların toplamının \%3'ü alınarak hesaplara dâhil edilmiş, arazinin kira bedeli hesaplanırken bölgede benzer araziler için alınan kira miktarı dikkate alınmıştır.

Maliyet hesaplamasında “Tek Ürün Bütçe Analiz Yöntemi” kullanılmıştır. Bir üretim döneminde yalnızca bir ürün üretiliyorsa, basit maliyet hesaplama yöntemi kullanılmaktadır. Basit maliyette, ilgili ürünün üretilmesi için yapılan toplam masraflar, üretilen ürün miktarına bölünmektedir (Çetin ve Tipi, 2011).

Gayrisafi üretim değeri; tarımsal faaliyet sonucu elde edilen ve bir pazar değeri bulunan bitkisel ürün miktarlarının, birim satış fiyatlarıyla çarpılması sonucu elde edilmektedir (Erkuş ve ark., 2005). Bu çalışmada toplam üretim miktarı birim fiyat ile çarpılarak Gayrisafi üretim değeri hesaplanmıştır.

Brüt kar, işletmede mevcut kıt üretim vasıtalarının kullanımı bakımından, üretim faaliyetlerinin rekabet güçlerinin belirlenmesinde önemli bir başarı ölçüsüdür. Brüt kar, gayrisafi (brüt) üretim değerinden, değişen masraflar düşülerek hesaplanmıştır. Hesaplanan maliyet bedelleri dolar cinsinden belirlenirken 2016 yılı ortalama dolar kuru 3.01798 TL olarak alınmıştır (TCMB, 2016).

\section{BULGULAR VE TARTIŞMA}

Iğdır'da domates üretimi yapan üreticiler ile yapılan anketlerden elde edilen veriler değerlendirilmiş olup dekara ve kg'a domates maliyetini oluşturan kalemler tespit edilmiştir. Bu amaçla materyal değeri ve miktarı, makine ve insan gücü ile uygulama sayısı ve birim maliyetleri hesaplanmış olup 2016 yılı fiyatları ile yapılan domates maliyet analizi Çizelge 2'de verilmiştir.

Çalışmaya dâhil edilen Iğdır İli domates üreticilerinin 1-15 dekar arasında olmak üzere ortalama 6.07 dekarlık alanda domates ürettikleri belirlenmiştir. Domates üretiminde ekim işleminde her biri 0.12 \$ dan dekara 146.96 \$ değerinde 1232 adet fide dikilmiştir. Bakım işlemlerinde ise tonu 16.52 \$ olan çiftlik gübresinden dekara 8.97 \$ değerinde $543 \mathrm{~kg}$ çiftlik gübresi, tonu ortalama 931 \$ olan 61.68 \$ değerinde $66.20 \mathrm{~kg}$ katı ve sıvı suni gübre, kg’1 21 \$ dan dekara $9.90 \$$ değerinde $0.47 \mathrm{~kg}$ ilaç atılmıştır.

Çizelge 2'de görüldüğü gibi domates üretim maliyetlerinin \%8.06'sını (66.99 \$) sabit masraflar oluştururken, \%91.94'ünü ise (763.90 \$) değişir masraflar oluşturmaktadır. Sabit masraflar içerisinde en fazla payı \%65.78 ile (44.07 \$) tarla kirası alırken, değişir masraflar içerisinde en fazla payı \%45.18 ile (345.32 \$) hasat ve taşıma bedeli almakta olup bunu \%27.21'ini (207.97 \$) toprak hazırlığı masrafları ve \%23.02'sini (175.97 \$) bakım masrafları izlemektedir. $\left.\mathrm{da}^{-1}\right)$

Birim maliyet $\left(\mathrm{kg} \mathrm{da}^{-1}\right)$ : Üretim masrafları toplamı-Mazot ve gübre desteği/Domates verimi ( $\mathrm{kg}$

Birim maliyet $\left(\mathrm{kg} \mathrm{da}^{-1}\right): 830.90-3.64 / 5454.76=0.15 \$$

Iğdır İlinde domates üretim maliyetlerinin belirlendiği çalışmada hasat öncesi ve sonrası ürün kayıpları incelenmemesine karşın Tatlıdil ve ark. (2004) Ankara'da sırık ve bodur domates çeşitlerinde hasat öncesi ve hasat döneminde ürün kayıları nedeni ile domates maliyetinin $0.03 \$$ arttığını bildirmişlerdir. Keskin ve ark. (2010) domates üretiminde en düşük maliyetlerin 0,066-0,073 \$ $\mathrm{kg}^{-1}$ arasında değiştiğini, Özkan ve ark. (2011) Antalya ili serada domates üretiminde dekara net kârı 1038.07 
\$ ve brüt kârı ise 3334.35 \$, Eskişehir'de $0,096 \$ \mathrm{~kg}^{-1}$ ve Antalya, Bursa ve Balıkesir'de $0.269 \$ \mathrm{~kg}^{-1}$ olarak hesaplarken Şili (2013) Samsun'un Bafra ilçesinde domateste dekara 354.55 \$ saf hasıla elde edildiğini belirtmiştir. Engindeniz ve Coşar (2013) İzmir'de dekara elde edilen ortalama net karı, sofralık domates için 191.13 \$, salçalık domates için 74.61 \$ olarak bulduğundan Iğdır' da sofralık ya da salçalık üretimin avantajları araştırılabileceği belirlenmiştir. Sipahioğlu (2014) Antalya ili tarım işletmelerinde domates üretiminde dekara net kârı ve brüt kârı 1466.41 \$ ve 3203.89 \$ olarak belirlerken, Ukav (2018) domates üretim masraflarının $235.39 \$ \mathrm{da}^{-1}$ olduğunu birim fiyatın $0.207 \$ \mathrm{~kg}^{-1}$, dekar başına toplam gelirin 401.87 \$ ve net kârın ise 166.48 \$ olduğunu hesaplamıştır.

Çizelge 2. Domates üretim maliyet tablosu

\begin{tabular}{|c|c|c|c|c|c|c|c|c|c|c|}
\hline \multirow{2}{*}{ Üretim işlemleri } & \multirow{2}{*}{ İşlem tarihi } & \multicolumn{2}{|c|}{$\begin{array}{l}\text { Kullanılan } \\
\text { işgücü }\end{array}$} & \multicolumn{2}{|c|}{$\begin{array}{l}\text { Kullanılan } \\
\text { çeki gücü }\end{array}$} & \multirow{2}{*}{$\begin{array}{l}\text { Kullanılan } \\
\text { ekipmanlar }\end{array}$} & \multicolumn{4}{|c|}{ Kullanılan materyal } \\
\hline & & Saat & $\begin{array}{c}\text { Tutar } \\
(\$)\end{array}$ & Saat & $\begin{array}{c}\text { Tutar } \\
(\$)\end{array}$ & & Cinsi & Miktar & $\begin{array}{c}\text { Tutar } \\
(\$)\end{array}$ & $\begin{array}{c}\text { Toplam masraf } \\
(\$)\end{array}$ \\
\hline I. Toprak hazırlığ & & & & & & & & & & $207.97(\% 27.21)$ \\
\hline a, Birinci sürüm & Kasım - Mayıs & 0.26 & 1.16 & 0.26 & 7.92 & Pulluk & Yakit (Lt) & 2.30 & 2.97 & 12.04 \\
\hline b. İkinci sürüm & Nisan - Mayıs & 0.20 & 0.89 & 0.20 & 6.09 & Pulluk & Yakit (Lt) & 2.00 & 2.58 & 9.54 \\
\hline $\begin{array}{l}\text { c. Tırmık, kültivatör, } \\
\text { diskaro }\end{array}$ & Mart - Mayıs & 0.26 & 1.36 & 0.26 & 8.56 & $\begin{array}{l}\text { Kazayağ1- } \\
\text { tapan }\end{array}$ & Yakit (Lt) & 2.36 & 3.04 & 12.96 \\
\hline d. Karık açma & Mart - Mayıs & 0.12 & 0.40 & 0.12 & 1.97 & Traktör & Yakit (Lt) & 0.88 & 1.13 & 3.50 \\
\hline e. Ekim & Nisan - Mayıs & 9.49 & 22.94 & - & - & Elle & $\begin{array}{l}\text { Fide (adet } \\
\left.\mathrm{da}^{-11^{\prime}}\right)\end{array}$ & 1232 & 146.96 & 169.90 \\
\hline II. Bakım & & & & & & & & & & $\mathbf{1 7 5 . 9 7}(\% 23.02)$ \\
\hline a. Çiftlik gübresi & Kasım - Haziran & 0.16 & 0.34 & 0.16 & 3 & Traktör & $\begin{array}{l}\text { Ç. gübre } \\
\left(\mathrm{kg} \mathrm{da}^{-1}\right)\end{array}$ & 543 & 8.97 & 12.13 \\
\hline b. Kimyasal gübre & Kasım - Haziran & 1.27 & 4.75 & 0.04 & 1.67 & $\begin{array}{l}\text { Traktör-Sirt } \\
\text { pompası }\end{array}$ & $\begin{array}{l}\text { K. gübre } \\
\left(\mathrm{kg} \mathrm{da}^{-1}\right)\end{array}$ & 66.20 & 61.68 & 68.11 \\
\hline c. Sulama & Nisan - Ağustos & 11.99 & 29.55 & - & - & & $\begin{array}{l}\text { Su ücreti } \\
\left(\mathrm{y} 1 \mathrm{da}^{-1}\right)\end{array}$ & & 12.09 & 41.65 \\
\hline d. İlaçlama & Ekim-Mayıs & 3.48 & 12.48 & - & - & Pülverizatör & $\begin{array}{l}\text { İlaç } \\
\left(\mathrm{kg} \mathrm{da}^{-1}\right)\end{array}$ & 0.47 & 9.90 & 22.38 \\
\hline e. Çapalama & Nisan - Haziran & 12.85 & 31.53 & - & - & & Elle & & & 31.53 \\
\hline III. Hasat & & & & & & & & & & $\mathbf{3 4 5 . 3 2}(\% 45.18)$ \\
\hline a. Hasat & Temmuz-Ekim & 82 & 204.83 & & & Elle & $\begin{array}{l}\text { Sepet (adet } \\
\mathrm{da}^{-1} \text { ) }\end{array}$ & 341.09 & 110.76 & 315.59 \\
\hline b.Taşıma & Temmuz-Ekim & & & & & Nakliye aracı & & & & 29.73 \\
\hline $\begin{array}{l}\text { IV. Döner sermaye faizi } \\
(\mathrm{I}+\mathrm{II}+\mathrm{III}) * \% 4.8\end{array}$ & & & & & & & & & & $34.67(\% 4.54)$ \\
\hline $\begin{array}{l}\text { A-Değişen masraflar } \\
\text { toplamı }\end{array}$ & & & & & & & & & & $763.90(\% 91.94)$ \\
\hline $\begin{array}{l}\text { a. Genel idare gideri } \\
(\mathrm{A} * \% 3)\end{array}$ & & & & & & & & & & $22.92(\% 34.22)$ \\
\hline b. Tarla kirası & & & & & & & & & & $44.07(\% 65.78)$ \\
\hline $\begin{array}{l}\text { B. Sabit masraflar } \\
\text { toplamı }\end{array}$ & & & & & & & & & & $66.99(\% 8.06)$ \\
\hline $\begin{array}{l}\text { C. Üretim masrafları } \\
\text { toplamı }(A+B)\end{array}$ & & & & & & & & & & $830.90 \underline{(\% 100)}$ \\
\hline $\begin{array}{l}\text { D. Domates verimi } \\
\left(\mathrm{kg} \mathrm{da}^{-1}\right)\end{array}$ & & & & & & & & & & 5454.76 \\
\hline $\begin{array}{l}\text { E. Domates satış } \\
\text { fiyatı }\left(\mathrm{TL} \mathrm{kg}^{-11^{\prime}}\right)\end{array}$ & & & & & & & & & & 0.29 \\
\hline F. GSUD $\left(\mathrm{TL} \mathrm{da}^{-1}\right)$ & & & & & & & & & & 1608.61 \\
\hline $\begin{array}{l}\left.\text { G. Brüt Kâr (TL da }{ }^{-1}\right) \\
\text { (F-A) } \\
\left.\text { H. Net Kâr (TL da }{ }^{-1}\right)\end{array}$ & & & & & & & & & & 844.70 \\
\hline$(\mathrm{F}-\mathrm{C})$ & & & & & & & & & & 777.71 \\
\hline
\end{tabular}

Birim maliyet $\left(\mathrm{TL} \mathrm{kg}^{-1}\right) \mathrm{C}-3,64 / \mathrm{D}: 0.15 \$$ (Mazot ve gübre desteği $3.64 \$ \mathrm{da}^{-1}$ ) $\quad$ *Motorin fiyatı : 1.29 \$ LT ${ }^{-1}$

İşletmeler ortalama olarak dekara $5454.76 \mathrm{~kg}$ üretim yapmıştır. Birim maliyet $0.15 \$ \mathrm{~kg}^{-1}$, ürün satış fiyatı $0.29 \$ \mathrm{~kg}^{-1}$, dekara GSÜD 1608 \$ olarak belirlenmiştir. İşletmelerin dekara ortalama 777.71 
\$ kâr elde ettiği belirlenmiştir. Karaman ve Yılmaz (2006) Antalya ilinde domates yetiştiriciliğinde, bombus arısı kullanan işletmelerde \%19.11 oranında daha fazla gayri safi üretim değeri elde edildiğini açıklamış olmalarına karşın Iğdır domates üretiminde bombus arısının gayri safi üretim değerine katkı sağlaması amacıyla kullanılması araştırılabilir. Örük ve Engindeniz (2019) Muğla'da örtü altı domates yetiştiriciliğinin ekonomik analizi çalışmalarında tek ürün yetiştiriciliğinde net kârın 692-783 \$ da ${ }^{-1}$ arasında olduğunu belirlemişlerdir. Suleiman ve ark. (2019) Nijerya'da domates üreticilerinin kârlı bir şekilde üretim yaptıklarını ancak, çiftçilerin sürekli olarak kaynak kullanım verimliliği yaratmaları gerektiğini, yani kaynak israfını önleyecek çalışma alanında sürdürülebilir üretime dikkat etmeleri gerektiklerini belirtirken Iğdır domates üreticilerinin özellikle salma sulama ile kaynak verimliliği konusuna dikkat etmedikleri belirlenmiştir.

\section{SONUÇ}

Türkiye'nin doğu sınırında bulunan ve doğunun Çukurovası olarak bilinen Iğdır ili tarım üreticisi için domates üretimi önemli bir faaliyet olarak belirlenmiştir. Iğdır'da domates verim düzeyi Türkiye ortalamasının yarısı kadar olmasına karşın doğru yetiştirme tekniklerinin uygulanması ile verim düzeyinin yükseltilebileceği anlaşılmaktadır. Iğdır ili domates üreticisi 2016 yılında işletme başına ortalama $6.07 \mathrm{da}$ alanda domates üretmiş, $5454.876 \mathrm{~kg} \mathrm{da}^{-1}$ verim almış, kg'ını 0.15 \$'a ürettiği domatesi 0.29 \$'dan satmıştır. Domates üreten işletmelerin domates üretim alanlarını artırarak üretime devam etmeleri gelir düzeylerinin artmasına katkı sağlayacağı gibi Iğdır ve civar illerdeki tüketicilerin uygun fiyatla ve yeterli miktarda domates temin edebilmelerine imkân verecektir. Bölgede domates işleme sanayinin kurulması ile domatesin salça, konserve vb. ürünlere işlenmesi sağlanacak ve ayrıca ürün pazarlama kooperatiflerinin kurulması ile daha yüksek fiyata ürün satışı gerçekleştirilebilecektir. Domates maliyeti içerisinde toprak hazırlığı, bakım ve hasat masrafları önemli masraf unsurları olarak belirlendiğinden karar alıcıların ürün maliyetlerinin düşürülmesi açısından yakıt, gübre, ilaç vb. girdilerde sübvansiyon uygulamalarına gitmeleri önerilebilir. Bölge üreticilerine Iğdır Üniversitesi ve Tarım İl Müdürlüğü uzmanlarınca domates yetiştirme teknikleri konusunda uygulamalı eğitimlerin verilmesi domates veriminin artırılması bakımından önem arz etmektedir. Enflasyon ve ithalattan kaynaklı tarımsal girdi fiyatlarındaki değişikliklerden dolayı ürün maliyet ve kâr düzeyleri değişeceğinden akademik açıdan benzer çalışmaların yapılmasına devam edilmesi gerekmektedir.

\section{TEŞEKKÜR}

$\mathrm{Bu}$ çalışma, Iğdır Üniversitesi Bilimsel Araştırma Projeleri Koordinasyon Birimi tarafından “2016-FBE-L06” kodlu proje ile desteklenmiştir.

\section{KAYNAKLAR}

Bhowmik D, Sampath Kumar KP, Paswan S, Srivastava S, 2012. Tomato-A Natural Medicine and Its Health Benefits. Journal of Pharmacognosy and Phytochemistry. 1(1): 33-43.

Çetin E, Bahşi N, 2019. Tarımsal üretim gerçekleştiren işletmelerin faaliyetlerinin hedef maliyet yöntemine göre değerlendirilmesi. Uluslararası Toplum Araştırmaları Dergisi, 13(19), 2365-2380.

Çetin B, Tipi T, 2011. Tarım Muhasebesi. Uygulamalı Örneklerle. Nobel Yayın Dağıtım, 167 s., Ankara.

Engindeniz S, Öztürk Coşar G, 2013. İzmir'de Domates Üretiminin Ekonomik ve Teknik Etkinlik Analizi. Ege Üniv. Ziraat Fak. Derg., 50(1): 67-75.

Erkuş A, Bülbül M, Kıral T, Açıl AF, Demirci R, 2005. Tarım Ekonomisi. Ankara Üniversitesi Ziraat Eğitim Araştırma ve Geliştirme Vakfı Yayınları No:5, Ankara.

FAO, 2018. Food and Agriculture Organization of the United Nations. http://www.fao.org/faostat/en/\#data/QC (Erişim Tarihi: 09.03.2020) 
Gutierrez EEV, 2018. An Overview of Recent Studies of Tomato (Solanum lycopersicum spp) from a Social, Biochemical and Genetic Perspective on Qquality Parameters. Swedish University of Agricultural Sciences. Alnarp-Sweden. 8 pp.

Karadaş K, 2016. Ağrı İli Tarım İşletmelerinde Buğday Üretim Maliyetlerinin Hesaplanması. Alınteri Zirai Bilimler Dergisi, 31(B): 33-41.

Karagölge C, Kızıloğlu S, Yavuz O, 2013. Tarım Ekonomisi Temel İlkeleri. Atatürk Üniversitesi Ziraat Fakültesi Yayınlar1 No:324, 112 s., Erzurum.

Karaman Y, Yılmaz İ, 2006. Cam Serada Domates Yetiştiriciliğinde Bombus Arısı Kullanımının Üretim Girdileri ve Karlılık Üzerine Etkisi. Anadolu, J. of AARI 16(2): 90-109.

Keskin G, Gül U, 2004. Domates. Tarımsal Ekonomi Araştırma Enstitüsü T.E.A.E-Bakış, Sayı:5, Nüsha:13, Ankara.

Keskin G, Tatlidil FF, Dellal I, 2010. An Analysıs of Tomato Productıon Cost and Cabor Force Productıvity in Turkey. Bulgarian Journal of Agricultural Science, 16(6): 692-699.

Kıral T, Kasnakoğlu H, 1999. Tarımsal Ürünler İçin Maliyet Hesaplama Metodolojisi ve Veri Tabanı Rehberi. Tarımsal Ekonomik Araştırmalar Enstitüsü, 297 s., Ankara.

Muratore G, Rizzo V, Licciardello F, Maccarone E 2008. Partial Dehydration of Cherry Tomato at Different Temperature and Nutritional Quality of the Products. Food Chemistry, 111: 887-891.

Örük G, Engindeniz S, 2019. Muğla İlinde Örtüaltı Domates Üretiminin Ekonomik Analizi Üzerine Bir Araştırma. Ege Üniv. Ziraat Fak. Derg., 56(3): 345-358.

Özkan B, Hatırlı SA, Öztürk E, Aktaş AR, 2011. Antalya İlinde Serada Domates Üretiminin Kâr Etkinliği Analizi. Tarım Bilimleri Dergisi - Journal of Agricultural Sciences, 17: 34-42.

Rehber E, Tipi Ç, 2015. Tarımsal İşletmecilik ve Planlama. Uludağ Üniversitesi Yayınları, Uludağ Üniversitesi Basımevi. No:2.05-049-0425, 318 s., Bursa.

Sipahioğlu C, 2014. Farklı Tarım Sistemlerinde Domates Üretiminin Maliyet Analizi. Uludağ Üniversitesi, Fen Bilimleri Enstitüsü, Yüksek Lisans Tezi (Basılmış).

SPSS, 2013. IBM SPSS Statistics 22.0 for Windows. Armonk, NY.

Suleiman NJ, Mani JR, Hudu MI, Baba D, Yusuf M, (2019). Cost-Benefit Analysis of Tomato Production Among Small-scale Farmers in Kano River İrrigation Project Area of Kano State, Nigeria. Journal of Agripreneurship and Sustainable Development (JASD) 2(1): 39-46.

Şili Ş, 2013. Samsun İli Bafra İlçesinde Domates Yetiştiren İşletmelerin Etkinlik Analizi. Ondokuz Mayıs Üniversitesi, Fen Bilimleri Enstitüsü, Yüksek Lisans Tezi (Basılmış).

Tatlıdil FF, Kıral T, Gündoğmuş E, Fidan H, Aktürk D, 2004. The Effect of Crop Losses during Pre-Harvest and Harvest Periods on Production Costs in Tomato Production in the Ayas and Nallihan Districts of Ankara Province. Turk J Agric For 29: 499-509.

TCMB, 2016. TCMB. Türkiye Cumhuriyet Merkez Bankası Döviz Kurları. http://www.tcmb.gov.tr/kurlar/kur2016_tr.html (Erişim Tarihi: 30.03.2020)

TÜİK, 2019. Türkiye İstatistik Kurumu. Bitkisel Üretim İstatistikleri. https://biruni.tuik.gov.tr/medas/?kn=92\&locale=tr (Erişim Tarihi: 24.09.2019)

Ukav İ, 2018. Adıyaman İlinde Üretimi Yapılan Bazı Sebzelerin Üretim Maliyetleri ve Kârlılıkları Üzerine Bir Araştırma. Türk Tarım-Gıda Bilim ve Teknoloji Dergisi, 6(9): 1285-1289.

Yamane T, 2010. Temel Örnekleme Yöntemleri. Gazi Üniv. Fen-Edebiyat Fak. İstatistik Bölümü Literatür Yayınlar1, No.53, 116 s., İstanbul. 